\title{
Compromised or Competent: Analyzing Twin Children's Social Worlds
}

\author{
Karen Thorpe and Susan Danby \\ School of Early Childhood, Queensland University of Technology, Brisbane, Australia
}

From conception twin children are compelled to share their environment and its resources. This includes social resources of attention from, and social interactions, with others. This special issue specifically focuses on the social world of twin children and addresses three key questions:

- How is the social world of twins different from that of a single-born child?

- Does the twin situation limit social experience and compromise social development?

- Does the twin situation enhance social experience and facilitate social competency?

The issue includes studies from a range of disciplines, including psychology, sociology, anthropology and behavioral genetics, and utilizes a range of approaches to the analysis and understanding of the processes and outcomes of twin children's social experiences.

\section{How Is the Social World of a Twin Different From That of a Single-Born Child?}

The twin situation presents a unique social situation that is different from the social world of a single-born child in three key ways. First, the twin child grows up alongside a child of the same age and, typically, developmental need. This circumstance presents competition for social resources but also the opportunity for a close, supportive and unique life-long relationship with an age peer. Second, twin children place unique demands on their carers. Parenting twins, particularly in the early years when dependency levels are high, is a very different task from that of parenting a single-born child, even when there is a sibling close in age (see Thorpe et al., 1991; Thorpe et al., 2003). Interactions are more often triadic, involving mother and two children, and contrasts with the dyadic, one-to-one interactions typically experienced by young single-born children. Third, twins have a social identity that attracts unique attention. Although twinning is increasingly more common, twinning is still relatively rare and a focus for cultural fascination (see Stewart, 2003). The status of being a twin, particularly for those who are identical, is highly visible, elicits social reaction and possibly mediates access to and quality of social interaction.
Twin children also actively create their social environment. Though the social circumstance of being a twin may set limitations or provide unique opportunities, the active choices and social engagements made by twin children also play a part in defining the twin situation. A number of papers included in this issue pick up on this theme. Two papers (Guo; Thorpe \& Gardner) examine twin children's friendships and suggest that friendship choices relate to the similarity of twin children. Thus, monozygotic (MZ) twins reinforce their similarity in their social environment by selecting friends who are similar to themselves, more often nominate their co-twin as a friend and share friends with their co-twin. This contrasts with dizygotic (DZ) opposite-sex pairs who have few shared friends and DZ same-sex pairs who, though less similar, are compelled to share a social pool. A key message is that the experience of being a twin varies for different types of twins. Bacon shows how children are actively involved in their social portrayal of the identity of twin. Some twin children actively foster their twin identity through appearance while others focus on individuality. Danby and Thorpe examine twin children's relationships with each other and how they negotiate the process of being a twin through their interactions. This paper, which focuses on DZ samesex twin girls, portrays a process of actively defining social identity through these interactions. DZ same-sex children are reported to experience more ambivalence (Thorpe \& Gardner) and more conflict (Danby \& Thorpe). Both papers document how twin children develop strategies to negotiate these circumstances.

\section{Risk and Resilience}

An important reason for the theorizing and empirical testing of the effects of the twin situation on social experience and social functioning is that the findings contribute to the understanding of processes of risk and resilience. It is well documented that twin children face biological adversity associated with higher rates of obstetric and perinatal risk in their early life (Hay \& Steed, 2005). It is perhaps less commonly acknowledged

Address for correspondence: Associate Professor Karen Thorpe, School of Early Childhood, Victoria Park Rd., Kelvin Grove, QLD 4059, Australia.E-mail: k.thorpe@qut.edu.au 
that twin children experience social adversity (Rutter \& Redshaw, 1991; Thorpe et al., 2003). Research studies on the effects of the social experience have examined the 'risk' of adverse effects on development deriving from the twin situation. A more recent notion is that such experiences may have long-term positive effects.

\section{Does Being a Twin Compromise Social Experience?}

Evidence that the twin situation constitutes a 'risk' for development derives from studies of social interaction within the home and centres on parent-child interactions in the first 3 years of life. Comparisons with singletons indicate that, in their early life, twins experience poorer quality of social interaction within the family (Thorpe et al., 2003). These effects are direct and also mediated through the impact of the additional and exceptional burden of caring for twins on the wellbeing of their parents. Studies of the patterns of family interactions suggest that, compared with single-born children, young twins spend more time with a child of the same age, less time in individual interactions with adults, have less sustained and more interrupted interactions with adults, and experience more control and less cognitively stimulating interactions (Rutter \& Redshaw, 1991; Thorpe et al., 2003). Even when compared to families with close spaced single-born children, twins have been found to experience poorer quality of interaction and less access to cognitively stimulating experiences. These differences in social interaction have been found to account for delays in language development compared to single-born children (Thorpe et al., 2003). Delayed development may also be associated with parental well-being. Mothers of twins have increased rates of maternal depression (Thorpe et al., 1991), which has been found to diminish the responsiveness of mothers to their young children, and are associated with poorer cognitive development (Murray \& Cooper, 1997).

Less is known about twin children's experiences in the social environment outside the home. Specific studies of twin children's social functioning outside the home are beginning to emerge and are evidenced in the collection presented in this issue (DiLalla; Hayashi et al.; Laffey-Ardley \& Thorpe). To date research has primarily focused on problems or deficits in twin children's development which may affect their broader social functioning, and problems become more apparent once the child moves to a broader social world outside the home. There has been a particular focus on language and behavior because twins have a higher risk of language delay and behavioral difficulties. A consistent finding in the comparison of twin and singletons is that, in the early years, twins lag behind singletons in language development (Rutter et al., 2003; Thorpe, in press). There are also reports of raised levels of attention-deficit hyperactivity disorder in twin populations (Levy et al., 1996). In this issue, Polderman and colleagues report on the level of behavioral difficulties and their heritability. Language and behavioural problems are potential impediments to accessing quality social experiences and establishing successful social relationships. For example, Hay and O'Brien (1987) studied twin children's progress following entry to preschool education. While it is often supposed that preschool education would enhance twin children's social experience and language development, such positive effects were not found. The authors suggest that the twin children, because their development was delayed, could not fully engage in the preschool program. In this issue, Hayashi and colleagues examine reports of appearance of 'twin language' and note that presence of older siblings and experience in preschool reduce parent reporting of twin language. This suggests that early experiences, external to the family, may promote language development. These studies, ostensibly presenting conflicting results, underscore the close interrelationship between developmental competencies and social experience.

Friendships are one potentially important source of information on the social functioning of twin children. In singleton populations, friendships have been found to be important predictors of long-term scholastic attainment and emotional health (see Hartup, 2000, for an excellent review). Existing data on friendships emerge from larger studies focused on twin children's development or educational progress (Koch, 1966; Preedy, 2001). These studies indicate that, while the mean number of friends does not typically differ, twin children's friendship patterns are distinguished by the sharing of friends. Preedy (2001), in a survey of more than 11,000 twins (4- to 5-year olds) entering their first school year, found that most twin children had friends in common (shared friends). Papers presented in this issue indicate clear variation in sharing of friends according to twin type and raise the issue of the different tasks of establishing relationships with others faced by MZ, DZ same-sex and DZ opposite-sex twins. What is not yet known is whether sharing friends constitutes a risk factor for development. Preedy also reports individual variation in number of friendships reported for twin pairs. In her sample, $20 \%$ of twin children had few friends other than their co-twin at school entry. An important question arising from this finding that has not yet been addressed by research is whether the twins who do not have friends at the commencement of school are those who have poorer developmental outcomes long-term.

An assessment of whether the twin situation constitutes a risk for social experience and social development also requires examining group differences between twins and singletons and assessing the individual differences within the twin group. The mediating effects of the relationship with co-twin, behavioral problems and language development are particularly important. The understanding of these associations and the mechanisms linking language, behavioral problems, social interactions and long-term outcomes is at an early 
stage. There is a need for greater clarity and specificity in describing this risk. Being a twin quite clearly has the potential to compromise social experience and development, but it is not clear how risk manifests as true adversity or otherwise. The development of resilience may result from twin children's experiences.

\section{Does Being a Twin Promote Social Competency?}

The notion that the twin situation might promote social competency is new. A recent large Finnish study of adolescents reported that age-peers rated twins as more socially adaptive than their single-born counterparts (Pulkkinen et al., 2003). This paper, the first to present data suggesting an advantage of twinning, has spawned interest in the idea that the twin situation might be a source of social learning. The finding from the Pulkkinen study of adolescents contrasts with the studies of twins in early childhood that indicate that the twin situation has negative effects on development. There are two explanations for these conflicting findings. The first is methodological. The Pulkkinen paper utilizes peer reporting whereas studies in early childhood rely on parent and teacher reporting. The second is theoretical. There may be developmental discontinuity between early childhood and adolescence. The twin situation may be a disadvantage for social development and competency early in life but an advantage at a later life stage. That is, there may be a resiliency effect: the apparently adverse experiences of early life provide skills that manifest as positive later in life.

There are a number of potential advantages associated with the social circumstances of being a twin that warrant consideration. The most likely candidate variables are the emotional support provided by the presence of a co-twin and the social learning that might derive from the need to negotiate and share from very early in life. Studies of singletons indicate that children who have greater competency in social skills, such as negotiating turn-taking and taking the perspective of another, are more likely to have supportive friendships and more positive developmental outcomes (Dunn, 2003). The twin situation certainly provides an environment for learning and rehearsing such skills. Further studies of the development of social cognition suggest that having siblings promotes understanding the perspective of another (Theory of Mind), a skill that underlies social functioning (Cassidy et al., 2005). There are few studies that have specifically focused on twin children or the twin situation in this respect, but this certainly warrants investigation. In this issue, Laffey-Ardley and Thorpe examine the specific circumstance of being an opposite-sex twin and its potential to promote social development.

\section{Analyzing the Social Worlds of Twins}

The body of research documenting the 'risk' attached to the twin situation, along with the recent evidence suggesting 'resilience' or even advantage accruing from the experience of twinship, identifies the social world of twins as a key area for future research. The evidence from studies of singleton populations indicates that social competence and associated effects, such as the formation and maintenance of supportive friendships, have long-term consequences for emotional health and life attainment (see Hartup, 2000). To date there are no such studies of twin populations. Such studies are required to understand how being a twin affects life chances. With the increase in twinning rates across the western world (Australian Bureau of Statistics, 2002; Martin et al., 2003) the importance of this focus grows. The study of twin populations also contributes to the broader understanding of mechanisms that link social experience to both short- and long-term well-being. Directions for future research include the asking of new questions and the application of new methods.

\section{New Questions — Long Term Impact, Process and Mechanism}

A key direction for research in the social world of twins is the undertaking of longitudinal studies. If we are to understand the mechanism that link early experiences as a twin, social skills (including communication) and longterm outcomes, the same twin population should be studied across the life course. Existing data bases from twin registries can clearly contribute. However, specifically designed studies which can utilize measures from emerging literature, such as those presented here, are also warranted.

\section{New Methods}

Research methods used in the study of social cognition, social and language development has seen dramatic advances in the last two decades. These advances have been underpinned by a changing conception of the child from a passive recipient of environment to that of an active agent in the construction of their own environment. There has been a shift in focus from children's deficits in comparison to adults, to a focus on their competencies. Behavioral genetics studies have made a major contribution to this advance in studies of development by identifying the active role of the child in creating environment (phenotype effect on environment), particularly in partialling out shared and nonshared environmental effects. Commensurately, advances have been witnessed in other disciplines with developmental psychology identifying the high levels of skill in the human infant and studies in the sociology of childhood identifying the active social agency of the child. The use of observation, interview and standard testing methods and the subsequent analytical techniques have increased in sophistication to match these changing conceptions. One major advance is data collection which seeks the view of the child.

\section{Child Accounts of Friendship and Social Interaction Are Needed to Understand the Learning Context Provided by Friendships}

Within the singleton literature, there are new understandings emerging of children's friendships and social interactions. This is in response to, in no small measure, 
new methods for researching with children (Christensen \& James, 2000; Corsaro et al., 2003; Danby \& Farrell, 2004, 2005). Four key themes are identified within childhood and singleton studies, and there is recent work emerging that draws on these themes to examine the twin situation.

First, the research focuses on understanding the experiences of children from their own perspectives. In this way, these types of studies advance beyond adult measurement and interpretation of children's social interaction to include observations of, and accounts from, the children. This requires the researchers (and readers) to understand that children are active in determining and constructing their own lives, and competent to report on how they think about and understand their social worlds. An innovation of this approach, which can be described as researching from the "child standpoint' (Mayall, 2002), is the application to twin populations (Danby \& Thorpe, 2004; Danby \& Thorpe, this issue).

Second, the research focus is on 'being a child' and not 'becoming an adult'. There is a new focus on understanding children's everyday experiences, not for considering how this impacts on their long-term and life trajectory, but rather for examining the here-andnow moments in their own right. Such a change of adult perspective then brings a change in analytic focus. This means that the studies are not futures-directed, but the research lens is located firmly within the children's everyday events and experiences, and within the local and particular (Danby, 2005). The focus is directed toward understanding how children engage in their everyday lives. This provides a new rationale for understanding the work of children, as they manage and organize their everyday activities, and is described as a practical accomplishment (Danby, 2005).

Third, the application of a sociological perspective to twinship has only been examined recently (Danby \& Thorpe, 2004; Stewart, 2003). These studies apply sociological perspectives in empirical studies of twinship. This approach makes a key contribution to understanding social interaction and quality of friendship in childhood. The quality and attributes of friendships are mapped by observing how children manage social interactions to reveal how children initiate and maintain friendship practices, build relational encounters and shape collective performances. This detailed process captures children's enactment of friendships and their meaning.

The fourth theme is the emergence of multidisciplinary approaches and methods embedded within both psychological and sociological approaches. For example, the recently awarded Australian Research Council study (Thorpe, Danby, Hay and Stewart) draws on a nested design that accommodates the need for a large sample size required to test the hypothesized Risk and Competency models and a smaller sample that allows for detailed interview and observation work. Multiple analyses of the same observation and interview data are conducted, allowing purposive sampling from the observation subsample for detailed analysis, and providing a dual perspective on the qualitative dimensions of friendship. This approach seeks to understand the relevance, connections and social relations involved in twins' friendships.

In the current issue the papers present a range of methodological approaches to the study of the social world of twins, including those taking the perspective of the child. The papers represent the beginning of study of the mechanisms and processes that link the well-documented difficulties experienced by twins in early childhood (such as language and access to quality interaction) to their long-term social well-being.

\section{References}

Australian Bureau of Statistics. (2002). Special article: Confinements resulting in multiple births. Year Book 2002.

Cassidy, K., Fineburg, D., Brown, K., \& Perkins, A. (2005). Theory of mind may be contagious, but you don't catch it from your twin. Child Development, 76, 97-106.

Christensen, P., \& James, A. (2000). Childhood diversity and commonality: Some methodological insights. In P. Christensen \& A. James (Eds.), Research with children: Perspectives and practices (pp. 160-178). London: Falmer Press.

Corsaro, W., Molinari, L., Hadley, K., \& Sugioka, H. (2003). Keeping and making friends: Italian children's transition from preschool to elementary school. Social Psychology Quarterly, 66, 272-292.

Danby, S. (2005). Preschool girls, conflict and repair. In J. Mason \& T. Fatore (Eds.), Taking children seriously (pp. 172-181). Children in Charge Series. London: Jessica Kingsley.

Danby, S., \& Thorpe, K. (2004, July). Negotiating conflict in a twin relationship. Paper presented at the International Congress on Twin Studies, Odense, Denmark.

Danby, S., \& Farrell, A. (2004). Accounting for young children's competence in educational research: New perspectives on research ethics. Australian Educational Researcher, 31, 35-50.

Danby, S., \& Farrell, A. (2005). Exploring consent and participation. In A. Farrell (Ed.), Exploring ethical research with children (pp. 49-67). Milton Keynes, UK: Open University Press.

Dunn, J. (2003). Emotional development in early childhood: A social relationship perspective. In R. J. Davidson, K. R. Scherer, \& H. H. Goldsmith (Eds.), Handbook of affective sciences. Oxford, UK: Oxford University Press.

Hartup, W. W. (2000). The company they keep: Friendships and their developmental significance. In W. Craig (Ed.), Childhood social development (pp. 61-84). Malden, MA: Blackwell. 
Hay, D., \& O’Brien, P. J. (1987). Early influences on the school social adjustment of twins. Acta Geneticae Medicae et Gemellologiae, 36, 239-248.

Hay, D. A., \& Steed, L. (2005). Adaptation and maladaptation in the multiple birth family. In I. Blickstein \& L. G. Keith (Eds.), Multiple pregnancy: Epidemiology, gestation and perinatal outcome (pp. 845-855). London: Parthenon Press.

Koch, H. (1966). Twins and twin relations. Chicago: University of Chicago Press.

Levy, F., Hay, D., McLaughlin, M., Wood, C., \& Waldman, I. (1996). Twin sibling differences in parental reports of $\mathrm{ADHD}$, speech, reading and behaviour problems. Journal of Child Psychology \& Psychiatry \& Allied Disciplines, 37, 569-578.

Martin, J. A., Hamilton, B. E., Sutton, P. D., Ventura, S. J., Menacker, F., \& Munson, M. L. (2005). Births: Final data for 2003. National Vital Statistics Report, September 8, 54, 1-116.

Mayall, B. (2002). Towards a sociology for childhood: Thinking from children's lives. Buckingham, UK: Open University Press.

Murray, L., \& Cooper, P. J. (Eds.). (1997). Postpartum depression and child development. New York: Guilford Press

Pulkkinen, L., Vaalamo, I., Hietala, R., Kaprio, J., \& Rose, R. J. (2003). Peer reports of adaptive behaviour in twins and singletons: Is twinship a risk or an advantage? Twin Research, 6, 106-118.
Preedy, P. (2001). Are multiple birth children different from singletons? Meeting the educational needs of multiple birth children upon school entry. Unpublished doctoral dissertation, University Of Birmingham, UK.

Rutter, M., \& Redshaw, J. (1991).) Annotation. Growing up as a twin: Twin-singleton differences in psychological development. Journal of Child Psychology and Psychiatry, 32, 885-895.

Rutter, M., Thorpe, K. J., Greenwood, R., Northstone, K., \& Golding, J. (2003). Twins as a natural experiment to study the causes of language delay: I. Examination of obstetric and perinatal environment. Journal of Child Psychology and Psychiatry, 44, 326-341.

Stewart, E. A. (2003). Exploring twins: Towards a social analysis of twinship. Basingstoke, UK: Palgrave.

Thorpe, K. (in press). Best practice: Twin children's language development. Early Human Development.

Thorpe, K. J., Golding, J., MacGillivray, I., \& Greenwood, R. (1991). A comparison of the prevalence of depression in the mothers of twins and the mothers of singletons. British Medical Journal, 302, 875-878.

Thorpe, K., Rutter, M., \& Greenwood, R. (2003). Twins as a natural experiment to study the cause of mild language delay: II. Family interaction differences. Journal of Child Psychology and Psychiatry, 44, 342-355. 